\title{
Studies on Molecular Interactions of Bromoform and Ethyl Bromide at Four Different Temperatures
}

\author{
K. Umamakeshvari ${ }^{1}$ and U. Sankar ${ }^{2}$ \\ ${ }^{1}$ (Department of Physics, St. Johns College, Palayamkottai, India.) \\ ${ }^{2}$ (Department of Physics, Sri KGS Arts College, Srivaikuntam, India)
}

\begin{abstract}
Refractive indices of Bromoform and benzene, Ethyl bromide and benzene with five different concentrations at four different temperatures are measured using Abbe's refractometer. The experimental values are compared with those estimated by the mixing rules Eyring-John (EJ), Gladstone-Dale (G-D), Newton $(\mathrm{Nw})$ and Heller $(\mathrm{H})$ methods. Comparison of various mixing rules has been expressed in terms of root mean square deviation (RMSD).
\end{abstract}

Keywords: Refractive index, Abbe's refractometer, Benzene, Bromoform, Binary Mixtures, Mixing Rules.

\section{Introduction}

Dielectric studies of binary mixtures of pure polar liquids at static and optical frequencies can provide information about molecular structure and intermolecular interaction.[1-5]. Many researchers have attempted to get insight into the nature and degree of interactions that are present in polar liquid mixtures using the refractive indices measurements. Benzene evaporates in to air very quickly and dissolves slightly in water. It is highly flammable and is formed from both natural processes and human activities. Benzene is a colourless liquid with a sweet odor. Use benzene, to make other chemicals which are used to make plastics, resins, and nylon and synthetic fibers. Bromoform was used as a solvent, sedative, and flame retardant, but now it is mainly used as a laboratory reagent. Bromoforms high density makesit useful for sepapartion of minerals by density. When two samples are mixed with bromoform and then allowed to settle, the top layer will contain minerals lighter than bromoform, and the bottom layer will contain heavier minerals. Ethyl bromide is used as a solvent, as an anesthetic in medicine, as a refrigerant, as a fumigant. Many researchers have been studied the theoretical refractive index measurements by the refractive index mixing rules [6-8]. In the present study, we report the experimental and eoretical refractive index of binary mixtures, from these the validity of the mixing rules have been analyzed.

\section{Experimental Details}

Benzene (AR grade), Bromoform (AR grade)and ethyl bromide (AR grade) were commercially obtained from S D fine- Chem Limited (India) and used without further purification. Binary mixtures of bromoform and ethyl bromide with benzene were prepared at five different concentrations by volume. Assuming ideal mixing behaviour the concentration was converted into the mol fraction..The values of refractive indices of pure liquids, and of the binary mixtures have been determined by using Abbe's refractometer at wavelength of sodium D-light. The maximum measurement error in $\mathrm{n}$ value is $\pm 0.02 \%$. The measurement accuracy in refractive index is $0.3 \%$.

\section{Results And Discussion}

Measured values of refractive index of bromoform and ethyl bromide with benzene mixtures are presented in TABLE 1.

TABLE 1.Variation of refractive indices (n) at different molefractions of Bromoform (X2)+ Benzene (X1) and Ethylbromide + benzene at different temperatures

\begin{tabular}{|c|c|c|c|c|}
\hline \multirow{2}{*}{$\begin{array}{c}\text { Temperature } \\
\text { K }\end{array}$} & \multicolumn{2}{|c|}{ Bromoform + Benzene } & \multicolumn{2}{c|}{ Ethyl Bromide + Benzene } \\
\cline { 2 - 5 } & $\mathbf{X 2}$ & $\mathbf{n}$ & $\mathbf{X 2}$ & $\mathbf{n}$ \\
\hline 303 & 0.054 & 1.502 & 0.052 & 1.491 \\
\cline { 2 - 5 } & 0.105 & 1.505 & 0.100 & 1.492 \\
\cline { 2 - 5 } & 0.155 & 1.508 & 0.151 & 1.488 \\
\cline { 2 - 5 } & 0.205 & 1.513 & 0.199 & 1.486 \\
\cline { 2 - 5 } & 0.260 & 1.519 & 0.246 & 1.481 \\
\hline
\end{tabular}

National Conference on Current Advancements in Physics $3^{\text {rd }} \& 4^{\text {th }}$ February 2017 


\begin{tabular}{|c|c|c|c|c|}
\hline \multirow{3}{*}{308} & 0.054 & 1.494 & 0.052 & 1.490 \\
\cline { 2 - 5 } & 0.105 & 1.501 & 0.100 & 1.489 \\
\cline { 2 - 5 } & 0.155 & 1.506 & 0.151 & 1.487 \\
\cline { 2 - 5 } & 0.205 & 1.511 & 0.199 & 1.483 \\
\cline { 2 - 5 } & 0.260 & 1.516 & 0.246 & 1.476 \\
\hline \multirow{3}{*}{313} & 0.054 & 1.493 & 0.052 & 1.487 \\
\cline { 2 - 5 } & 0.105 & 1.497 & 0.100 & 1.486 \\
\cline { 2 - 5 } & 0.155 & 1.503 & 0.151 & 1.483 \\
\cline { 2 - 5 } & 0.205 & 1.507 & 0.199 & 1.479 \\
\cline { 2 - 5 } & 0.260 & 1.513 & 0.246 & 1.474 \\
\hline \multirow{5}{*}{318} & 0.054 & 1.490 & 0.052 & 1.484 \\
\cline { 2 - 5 } & 0.105 & 1.494 & 0.100 & 1.482 \\
\cline { 2 - 5 } & 0.155 & 1.498 & 0.151 & 1.478 \\
\cline { 2 - 5 } & 0.205 & 1.504 & 0.199 & 1.476 \\
\cline { 2 - 5 } & 0.260 & 1.509 & 0.246 & 1.470 \\
\hline
\end{tabular}

\section{1estimation Models of Refractive Index}

Measured experimental refractive index values of the Bromoform+ Benzene and Ethyl bromide+ Benzene binary mixtures were compared to those estimated by four mixing rules which are shown in Table 2 were proposed by

Eyring-John (E-J)[9]

$n=n_{A} \phi_{A}^{2}+n_{B} \phi_{B}^{2}+2\left(\mathrm{n}_{\mathrm{A}} \mathrm{n}_{\mathrm{B}}\right)^{1 / 2}$

Gladstone- Dale (G-D)[10]

$n-1=\left(\mathrm{n}_{\mathrm{A}}-1\right) \phi_{\mathrm{A}}+\left(\mathrm{n}_{\mathrm{B}}-1\right) \phi_{\mathrm{B}}$

Newton (Nw)[11]

$n^{2}-1=\left(\mathrm{n}_{\mathrm{A}}^{2}-1\right) \phi_{\mathrm{A}}+\left(\mathrm{n}_{\mathrm{B}}^{2}-1\right) \phi_{\mathrm{B}}$

Heller $(\mathrm{H})[12]$

$\frac{\left(n-n_{A}\right)}{n_{A}}=\frac{3}{2} \times \frac{\left(\left(\frac{n_{B}}{n_{A}}\right)^{2}-1\right)}{\left(\left(\frac{n_{B}}{n_{A}}\right)^{2}+2\right)} \phi_{B}$

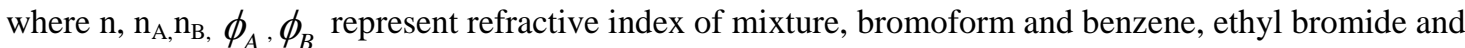
benzene,, volume fraction of bromoform and benzene, ethyl bromide and benzene respectively.

$$
\text { R.M.S.D }=\left(\frac{1}{m \sum\left(\mathrm{n}_{\mathrm{exp}}-\mathrm{n}_{\mathrm{cal}}\right)^{2}}\right)^{1 / 2}
$$

where $\mathrm{m}$ is the number of data points.

TABLE 2.Comparison of Exp Ref Index Data with Theoretical Values of the Binary Mixtures of Bromoform+ Benzene

\begin{tabular}{|c|c|c|c|c|c|c|c|c|c|c|c|c|c|c|c|c|}
\hline $\begin{array}{c}\text { Mole } \\
\text { Fraction }\end{array}$ & \multicolumn{4}{|c|}{ Eyring-John (EJ) } & \multicolumn{4}{|c|}{ Gladstone-Dale (G-D) } & \multicolumn{4}{c|}{ Newton (NW) } & \multicolumn{4}{c|}{ Heller(H) } \\
\hline 0.0539 & 1.543 & 1.575 & 1.507 & 1.539 & 1.506 & 1.483 & 1.459 & 1.436 & 1.506 & 1.483 & 1.460 & 1.436 & 1.506 & 1.483 & 1.459 & 1.436 \\
\hline 0.105 & 1.514 & 1.549 & 1.583 & 1.517 & 1.511 & 1.488 & 1.464 & 1.441 & 1.511 & 1.488 & 1.464 & 1.441 & 1.511 & 1.487 & 1.464 & 1.441 \\
\hline 0.155 & 1.505 & 1.541 & 1.576 & 1.512 & 1.516 & 1.492 & 1.469 & 1.445 & 1.516 & 1.493 & 1.469 & 1.446 & 1.515 & 1.492 & 1.469 & 1.445 \\
\hline 0.205 & 1.510 & 1.548 & 1.585 & 1.522 & 1.520 & 1.497 & 1.474 & 1.450 & 1.521 & 1.497 & 1.474 & 1.451 & 1.520 & 1.497 & 1.473 & 1.450 \\
\hline 0.2595 & 1.525 & 1.564 & 1.503 & 1.541 & 1.525 & 1.502 & 1.479 & 1.455 & 1.526 & 1.503 & 1.479 & 1.456 & 1.525 & 1.502 & 1.478 & 1.455 \\
\hline
\end{tabular}


TABLE 3.Comparison of Exp Ref Index Data with Theoretical Values of the Binary Mixtures of Ethyl Bromide+ Benzene

\begin{tabular}{|c|c|c|c|c|c|c|c|c|c|c|c|c|c|c|c|c|}
\hline \multirow{2}{*}{$\begin{array}{c}\text { Mole } \\
\text { Fraction }\end{array}$} & \multicolumn{4}{|c|}{ Eyring-John (EJ) } & \multicolumn{4}{|c|}{ Gladstone-Dale (G-D) } & \multicolumn{4}{|c|}{ Newton (NW) } & \multicolumn{4}{|c|}{ Heller(H) } \\
\hline & $3 \mathrm{~K}$ & $308 \mathrm{~K}$ & $313 \mathrm{~K}$ & $318 \mathrm{~K}$ & $3 \mathrm{~K}$ & $308 \mathrm{~K}$ & $313 \mathrm{~K}$ & 318 & $3 \mathrm{~K}$ & $308 \mathrm{~K}$ & $313 \mathrm{~K}$ & $318 \mathrm{~K}$ & $03 \mathrm{~K}$ & $308 \mathrm{~K}$ & $313 \mathrm{~K}$ & $18 \mathrm{~K}$ \\
\hline 0.0519 & 577 & & & & & & & & & & & & 97 & & & \\
\hline$x$ & & & & & & & & & & & & & & & & \\
\hline 5 & & & & & & & & & & & & & 9 & & & \\
\hline 98 & 54 & & & & & & & & 1.48 & & & & & & & \\
\hline 0.2461 & 563 & 1.516 & 1.568 & 1.520 & 1.482 & 1.46 & & & 1.482 & 1.46 & 1.44 & 1.42 & 1.482 & 1.46 & 1.44 & 1.4 \\
\hline
\end{tabular}

A close perusal from the tables shows that all theoretical mixing rules shows good agreement with the experimental values. The average percentage deviation obtained for the binary liquid systems benzene with bromoform shows good agreement than the another liquid systems. All the binary mixtures show better agreement in the lower concentration. This study shows that all the theoretical mixing rules are inter related well within the limits of the experimental error.[14-17].

TABLE 4.Values of Rmsd against Various Mixing Rules of Bromoform-Benzene Mixture

\begin{tabular}{|c|c|c|c|c|}
\hline \multirow{2}{*}{ Mixing rules } & \multicolumn{4}{|c|}{ RMSD } \\
\cline { 2 - 5 } & $\mathbf{3 0 3}$ & $\mathbf{3 0 8}$ & $\mathbf{3 1 3}$ & $\mathbf{3 1 8}$ \\
\cline { 2 - 5 } & \multicolumn{3}{|c|}{ Refractive index } \\
\hline Eyring -John & 10.468 & 3.8302 & 3.2356 & 6.6978 \\
\hline Gladstone-Dale & 30.455 & 14.669 & 5.952 & 3.73464 \\
\hline Newton & 28.798 & 15.0895 & 6.020 & 3.761 \\
\hline Heller & 31.262 & 14.487 & 5.922 & \\
\hline
\end{tabular}

TABLE 5.Values of Rmsd against Various Mixing Rules of Ethylbromide-Benzene Mixture

\begin{tabular}{|c|c|c|c|c|}
\hline \multirow{2}{*}{ Mixing rules } & \multicolumn{4}{|c|}{ RMSD } \\
\cline { 2 - 5 } & $\mathbf{3 0 3}$ & $\mathbf{3 0 8}$ & $\mathbf{3 1 3}$ & $\mathbf{3 1 8}$ \\
\cline { 2 - 5 } & \multicolumn{4}{|c|}{ Refractive index } \\
\hline Eyring -John & 2.9057 & 2.8188 & 2.7560 & 2.1831 \\
\hline Gladstone-Dale & 71.082 & 11.667 & 5.661 & 3.765 \\
\hline Newton & 68.680 & 11.786 & 5.679 & 3.769 \\
\hline Heller & 71.815 & 11.623 & 5.654 & \\
\hline
\end{tabular}

The Root Mean Square Deviation (RMSD) values for the Eyring-Johns (E-J), Gladstone-Dale (G-D), Newton $(\mathrm{Nw})$, and Heller $(\mathrm{H})$ are presented in table 3. As RMSD values indicate, refractive index for mixtures under consideration. A close similarity is observed between the E-J and G-D relations. The RMSD values for E$\mathrm{J}$ and G-D relations are found to be identical when volume additivity is assumed. The best predictions are observed for the E-J followed by G-D while the RMSD values predicted by Nw and Heller relations are relatively higher. Since the liquid mixtures of different nature and significantly different molecular sizes are considered, a particular relation provides good agreement at one place and deviates at others. This study indicates that all the theoretical mixing rules are interrelated in a simple quantitative manner and perform well within the limits of experimental error. The applicability of these semi-empirical relations for predicting refractive indices has also been emphasized by others

\section{Conclusions}

The refractive indices were reported for the liquid mixtures of benzene with bromoform and ethylbromide at $303 \mathrm{~K}, 308 \mathrm{~K}, 313 \mathrm{~K}$ and $318 \mathrm{~K}$.the variation in refractive index on mixing is calculated shows better agreement with the theoretical mixing rules. For the mixture of benzene and bromoform shows better than benzene- ethylbromide liquid systems. Eyring-John shows good results than the other theoretical relations and Heller shows maximum deviation. These deviations can be minimized to some extent by considering the change in volume of the liquid with refractivity during the mixing. 


\section{References}

[1]. R.J.Sengwa, S. Sankhla, V.Khatri, S.Choudhary, Static permittivity and molecular interactions in binary mixtures of ethanolamine with alcohols and amides, Fluid Phase Equilib, 293 ,2010, 137-140.

[2]. C.P. Smyth,Dielectric anisotropy and electrical properties of the copper phthalocyanine (CuPc): 4-4'-nHeptylcyanobiphenyl(7CB) composite liquid crystals, Molecular Interactions, Vol.II, John Wiley \&Sons Ltd,1980.

[3]. V.A. Rana, H.A. Chaube, Relative permittivity, density, viscosity,refractive index and ultrasonic velocity of binary mixture of ethylene glycol, monophenylether and 1-hexanol at different temperatures, J.Mol. Liq.187 ,2013, 66-73.

[4]. Balamurugan D, Kumar S \& Krishnan S, Dielectric relaxationstudies of higher order alcohol complexes with aminesJ Mol Liqs, $122,2005,11$.

[5]. C M Trivedi \& V A Rana, Static permittivity, refractive index, density and related properties of binary mixtures of pyridine and 1-propanol at different temperatures, 52 ,2014, 183-191.

[6]. Sangita Sharma, Jasmin Bhalodia, Jayesh Ramani \& Rignesh Patel . Density,excess molar volumes and refractive indices of $\beta$-pinene with o,m,p-xylene and tolueneat 303.15, 308.15 and $313.15 \mathrm{~K}$. Physics and Chemistry of liquids,49(6),2011, 765-776

[7]. Manapragada V Rathinam, Sudir Mohite and Manapragada S. Kumar,. Densities,Viscosities and Refractive Indices of binary mixtures of Diethyl oxalate with someKetones at $(303.15,308.15$ and 313.15)K. Journal of Chemical and Engineering Data, 55,2010, 5946-5952

[8]. Dyaneshwar S. Wankhede, Refractive indices for binary mixtures of propylene Carbonate. International Journal of Chemistry research, 2 2011,, 23-26

[9]. Eyring H \& John M S, Significant liquid structures,(John Wiley, New York), 1969.

[10]. Gladstone F \& Dale D, Philos Trans R Soc, $148,1858,887$.

[11]. Kurtz S S \& Ward A L J, Franklin Inst, 222 ,1936, 563.

[12]. Heller W, Phys Rev, 5,1945, 68.

[13]. Bottcher C F J \& Bordewijk P, Theory of Electrical Polarisation, Vol2.Elseiver, Amsterdam, 1978.

[14]. Sangita Sharma, Pragnesh B Patel, Rignesh S, Patel \& Vora, J J. Density a comparative refractive indexstudy on mixing properties of binary liquid mixtures of Eucalyptol with Hydro carbons at 303.15, 308.15 and 313.15K,EJournal of Chemistry, 4, 2007,343-349.

[15]. Narendra, K., Krishnamoorthy, P.,\& Srinivasu, Ch. Refractive indices of binary liquid mixtures at different temperatures, Asian Journal of applied sciences, 4, 2011, 535-541.

[16]. Anwar Ali, Anil Kumar Nain, Dinesh Chand \& Rizwan Ahamed, Viscosities and Refractive Indices of binary mixtures at different temperatures: An Experimental and Theoretical Study, Indian Journal of Chemistry, 44, 2005, 511-515.

[17]. M. Meenachiand P. Krishnamoorthy, Theoretical prediction of refractive index of Phenol with hydrocarbons at 303K, Mechanica Confab, 2, 2013, 2320-2491. 